\title{
Effect of Heat Treatment Processes on Microstructure and Mechanical Behavior of TC21 Titanium Alloy
}

\author{
Ramadan N. Elshaer ${ }^{1}$, Khaled M. Ibrahim ${ }^{1,2}$, Azza F. Barakat ${ }^{3}$, Reham R. Abbas ${ }^{3}$ \\ ${ }^{1}$ Central Metallurgical R \& D Institute, Cairo, Egypt \\ ${ }^{2}$ College of Engineering, Taibah University, Medina, KSA \\ ${ }^{3}$ Faculty of Engineering, Helwan University, Cairo, Egypt \\ Email: Ramadan_elshaer@yahoo.com
}

How to cite this paper: Elshaer, R.N., Ibrahim, K.M., Barakat, A.F. and Abbas, R.R. (2017) Effect of Heat Treatment Processes on Microstructure and Mechanical Behavior of TC21 Titanium Alloy. Open Journal of Metal, 7, 39-57.

https://doi.org/10.4236/ojmetal.2017.73004

Received: July 15, 2017

Accepted: August 28, 2017

Published: August 31, 2017

Copyright (c) 2017 by authors and Scientific Research Publishing Inc. This work is licensed under the Creative Commons Attribution International License (CC BY 4.0).

http://creativecommons.org/licenses/by/4.0/

\begin{abstract}
The effect of heat treatment on microstructure and tensile properties as well as wear behavior on TC21 (Ti-6Al-2Sn-2Zr-3Mo-1Cr-2Nb-Si, wt.\%) Ti-alloy was investigated. The samples were solution treated at $900^{\circ} \mathrm{C}$ for $15 \mathrm{~min}$ followed by furnace cooling to $800^{\circ} \mathrm{C}$ with a cooling rate $1^{\circ} \mathrm{C} / \mathrm{min}$ and holding for $20 \mathrm{~min}$, then the samples cooled down to room temperature either using water quenching (WQ) or air cooling (AC). Consequently, aging treatment was applied at $575^{\circ} \mathrm{C}$ for $4 \mathrm{hr}$. The microstructure feature showed a secondary $\alpha$ phase $\left(\alpha_{s}\right)$ precipitated in residual $\beta$ phase due to the step cooling from $900^{\circ} \mathrm{C}$ to $800^{\circ} \mathrm{C}$ inside furnace as well as the aging treatment. The highest wear rate was obtained for WQ samples due to increasing in volume fraction of $\alpha_{\mathrm{p}}(58 \%)$. However, the lowest wear rate was reported for WQ + Aging samples due to the high hardness. Optimum mechanical properties of the studied TC21 Ti-alloy were obtained for AC + Aging condition. A better combination of hardness, tensile properties, and wear resistance was achieved for AC + Aging samples, although their wear resistance was found to be slightly lower than that of WQ + Aging samples.
\end{abstract}

\section{Keywords}

TC21 Ti-Alloy, Cooling Rate, Aging, Microstructure, Tensile Properties, Wear

\section{Introduction}

Titanium alloys, especially $\alpha+\beta$ titanium alloys, are widely used in advanced aerospace applications, aero-engines and chemical industries. The combination of high strength-to-weight ratio, excellent mechanical properties and good cor- 
rosion resistance makes them the best material choices for some critical applications [1] [2] [3]. Titanium alloys have become one of the indispensable structure materials for airplanes. They are used in advanced airplanes up to $30 \%-50 \%$ weight of the total structure, for instance, $41 \%$ in F-22 fighters [4]. However, titanium alloys were reported to present a notoriously poor wear characteristic due to their low resistance to plastic shearing, low working hardening and low protection exerted by surface oxide formed as a consequence of high flash temperatures (induced by frictional heating) during dry sliding [5]. One of the main reasons behind poor tribological properties of titanium alloys is the low thermal conductivity [6]. The poor tribological behavior of titanium alloys is acting as high coefficients of friction, severe adhesive wear with a strong tendency to seizing and low abrasion resistance [7].

TC21 (Ti-6Al-2Sn-2Zr-3Mo-1Cr-2Nb-Si, wt.\%) alloy is a new category of ( $\alpha+$ $\beta)$ titanium alloys with high strength, toughness, and damage-tolerance properties. It belongs to eight-component system, which develops for structural application in advanced aircraft and aerospace [8]. In case using TC21 alloy as important structural aircraft parts such as landing gear and flap track, there will be a significant advantage on weight loss for the aircraft. Of course, these components are subjected to many stresses and friction wear. When their resistance to abrasion is improved, it must take into account the fatigue behavior [9] .

By applying a heat treatment technique, TC21 alloy can obtain a better combination of tensile properties, fracture toughness, and low fatigue crack growth rate. In such case, the performance and engineering application value will be better than the widely used conventional Ti6Al4V alloy [10]. TC21 alloy has an increased room temperature strength (>1100 MPa) [9] compared with Ti6Al4V alloy. TC21 alloy with excellent characteristics is expected to replace Ti6Al4V alloy, which is the most widely used at present. Solution and aging treatments have been chosen to optimize microstructure and tensile properties as well as wear property of TC21 alloy by changing solution temperatures and cooling rate after solution treatment [11] [12]. By applying such solution and aging treatments, fine secondary $\alpha$-phase will precipitate inside the $\beta$ grains.

Recently, a variety of studies investigated the effect of thermomechanical treatment [13], and oxidation treatment [14] on fatigue behavior of TC21 Ti-alloy [15]. However, detailed examination of the effect of heat treatment processes on wear behavior and tensile properties are rarely reported. Therefore, in the present study, the effect of applying duplex stage heat treatment with different cooling rates on microstructure, tensile properties as well as wear properties of TC21 Ti-alloy has been investigated.

\section{Experimental Work}

In this research, TC21 samples were received as bars with a diameter of $7 \mathrm{~mm}$ and $140 \mathrm{~mm}$ long. The $\beta$ transus temperature was experimentally determined that was approximately $960^{\circ} \mathrm{C}$. The chemical composition of the investigated TC21 alloy is given in Table 1 . 
Table 1. Chemical composition of as-received TC21 alloy, (wt.\%).

\begin{tabular}{cccccccc}
\hline $\mathrm{Al}$ & $\mathrm{Mo}$ & $\mathrm{Nb}$ & & $\mathrm{Sn}$ & $\mathrm{Zr}$ & $\mathrm{Cr}$ & $\mathrm{Si}$ \\
\hline 6.5 & 3.0 & 1.9 & & 2.2 & 2.2 & 1.5 & 0.09 \\
$\mathrm{Fe}$ & $\mathrm{C}$ & & $\mathrm{N}$ & & $\mathrm{H}$ & $\mathrm{O}$ & $\mathrm{Ti}$ \\
0.05 & 0.01 & & 0.01 & & 0.001 & 0.07 & $\mathrm{Bal}$. \\
\hline
\end{tabular}

The samples were solution treated at $900^{\circ} \mathrm{C}$ for $15 \mathrm{~min}$ to achieve equilibrium followed by furnace cooled to $800^{\circ} \mathrm{C}$ with a cooling rate $1^{\circ} \mathrm{C} / \mathrm{min}$ and holding for $20 \mathrm{~min}$. Then the samples cooled either using water quenching or air cooling. Consequently, aging treatment was applied at $575^{\circ} \mathrm{C}$ for $4 \mathrm{hr}$. The experimental procedure for the heat treatment process is shown in Figure 1. The samples for optical metallographic examination were prepared by mechanical polishing and then etching with a solution consisting of $3 \% \mathrm{HF}, 30 \% \mathrm{HNO} 3$ and $67 \% \mathrm{H}_{2} \mathrm{O}$. $\mathrm{X}$-ray diffraction (XRD) analysis was conducted on finely polished samples to identify the present phases. Vickers hardness measurements were carried out using Vickers hardness tester in accordance to ASTM E384-11 standard, with a load of $196 \mathrm{~N}(20 \mathrm{~kg})$ for $15 \mathrm{~s}$. Cylindrical samples with a gage length and diameter of 20 and $4 \mathrm{~mm}$, respectively, were machined for tensile testing according to ASTM E8-15 standard at room temperature using a strain rate of 0.5 $\mathrm{mm} / \mathrm{min}$.

Dry sliding wear test was conducted using pin-on-ring tribometer testing machine in accordance to ASTM G99-05 standard. The wear sample with a cylindrical shape of $7 \mathrm{~mm}$ in diameter and $12 \mathrm{~mm}$ long was fixed against a rotating hardened ring (outer diameter of $73 \mathrm{~mm}$ and surface hardness of $63 \mathrm{HRC}$ ). Prior to each test, sample and counterpart surfaces were ground with different emery papers up to 1000 grit and cleaned ultrasonically in acetone to avoid the presence of humidity and non-desirable deposits. The ring was rotated at different speeds, which yielded linear sliding speeds of $1,1.25,1.5,1.75$ and $2 \mathrm{~m} / \mathrm{s}$. An applied constant normal load of $20 \mathrm{~N}$ was used for a duration of $15 \mathrm{~min}$. During testing, a jet of compressed air was pointed at the edge of the ring to avoid accumulation of wearing debris on the ring. The weights of samples were measured before and after testing using electronic scales with $0.1 \mathrm{mg}$ accuracy. The test results were evaluated according to the loss in weight. The mean value of results from three experiments has been reported. Worn surface of some selected samples was examined and analyzed using XRD and FESEM in order to determine the post-experimental wear mechanisms.

\section{Results and Discussions}

\subsection{Microstructure Evolution}

\subsubsection{As-Received Condition}

The microstructure of as-received TC21 alloy consists mainly of primary equiaxed $\alpha$ phase and transformed $\beta$ matrix, as shown in Figure 2. The average 


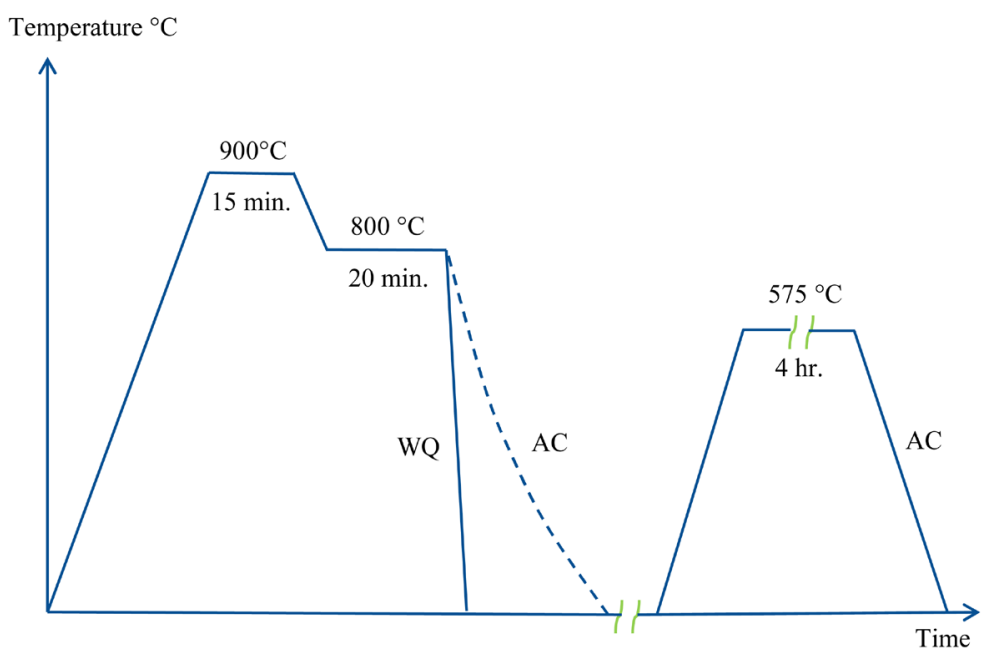

Figure 1. Experimental procedure for the heat treatment.

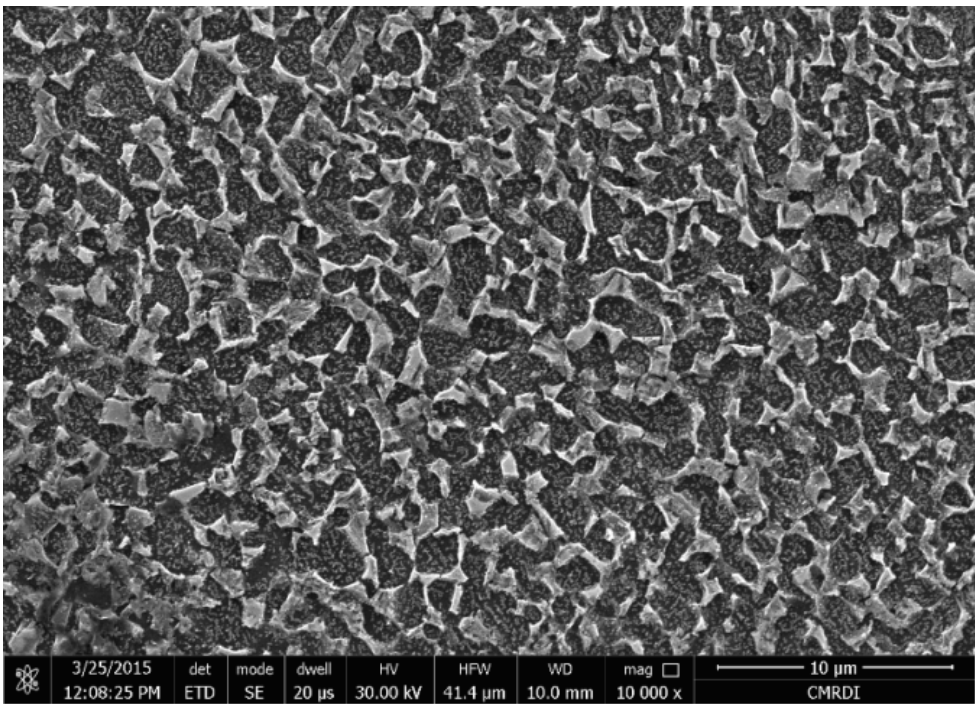

Figure 2. FESEM micrograph of as-received TC21 alloy bar.

diameter of $\alpha$ phase was approximately $2.5 \mu \mathrm{m}$ and its volume fraction approached to $65 \%$. The equiaxed $\alpha$ phase is distributed homogeneously in the entire field of view. The XRD pattern confirmed the presence of $\alpha$ and $\beta$ phase in the as-received TC21 alloy, Figure 3.

\subsubsection{Solution Treated Condition}

The microstructure of solution treated TC21 samples followed by either WQ or $\mathrm{AC}$ is shown in Figure 4. Generally, the volume fraction of primary equiaxed alpha phase $\left(\alpha_{\mathrm{p}}\right)$ increases with increasing of cooling rate. In addition, secondary alpha phase $\left(\alpha_{\mathrm{s}}\right)$ precipitated during the step cooling from $900^{\circ} \mathrm{C}$ to $800^{\circ} \mathrm{C}$. However, $\alpha_{\mathrm{s}}$ does not form during WQ due to high cooling rate that generates a high supersaturation in WQ condition as a result of diffusion of $\beta$ stabilizing elements in the $\beta$ phase. Subsequently, these elements will hinder the precipitation of secondary $\alpha$ phase. Step cooling in furnace mainly affects the growth of 


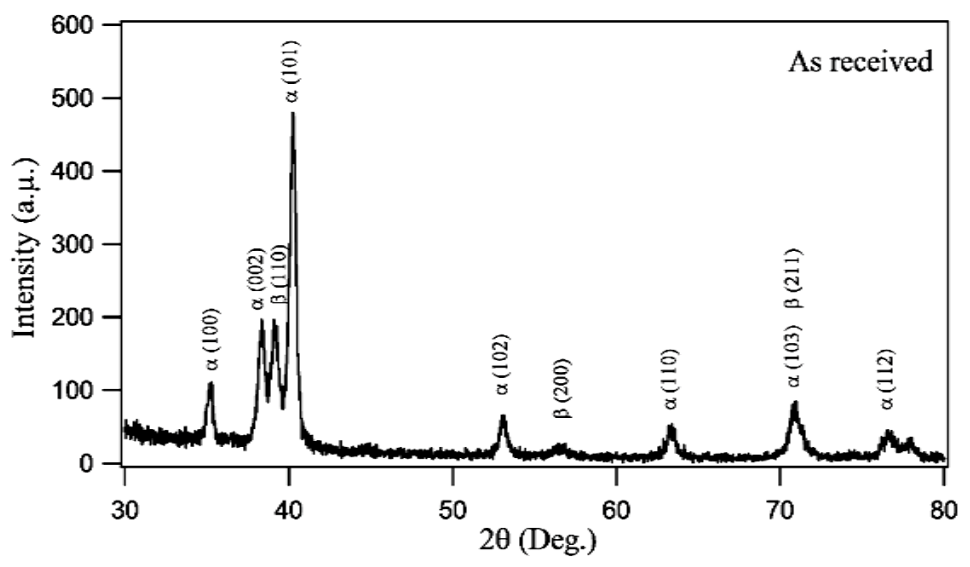

Figure 3. XRD pattern of the as-received TC21 alloy.
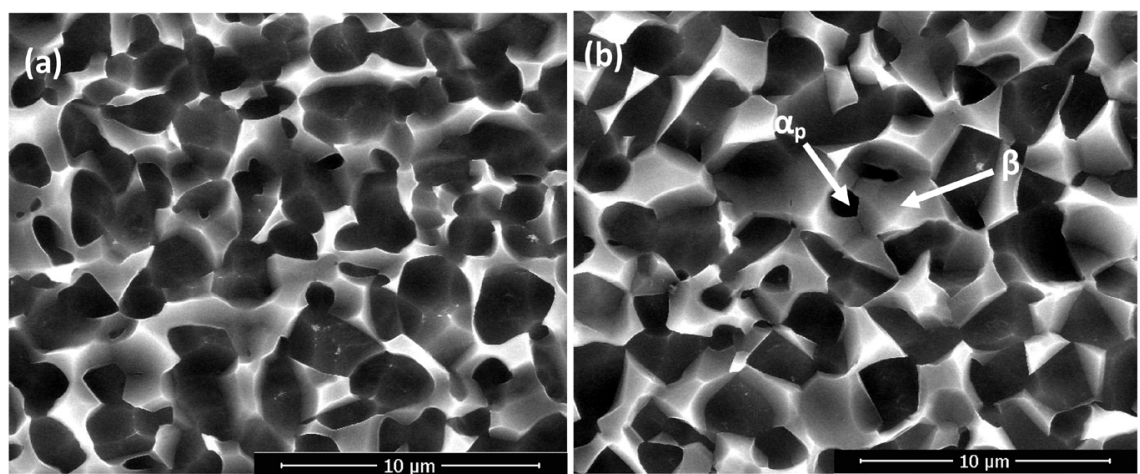

Figure 4. FESEM micrographs showing the microstructures of the conditions: (a) WQ and (b) AC.

primary $\alpha$ phase and precipitation of secondary $\alpha$ phase. For WQ condition, the grain size of primary $\alpha$ phase was in the range of $3.05 \mu \mathrm{m}$ and the volume fraction was about $58 \%$, and those in AC condition increased to $4.08 \mu \mathrm{m}$ and decreased to $52 \%$, respectively. Precipitation of secondary $\alpha$ phase at AC condition is due to increasing in cooling time. Therefore, it could be concluded that precipitation of secondary $\alpha$ phase could be obtained in a large amount by lower the cooling rate (AC) or applying a step cooling during solution treatment. Hence, a proper supersaturation could be considered as a critical factor for precipitation of secondary $\alpha$ phase in heat treating of TC21 alloy.

Based on the above discussion, the microstructure after WQ and AC conditions consists of primary equiaxed $\alpha$ phase, secondary $\alpha$ phase and transformed $\beta$ phase. Each phase has been identified by X-Ray diffraction analysis, as shown in Figure 5.

\subsubsection{Solution Treated + Aging Condition}

Solution treatment and aging is considered one of the processes usually applied on TC21 alloy [12]. The as-aged structure composed of an equiaxed $\alpha_{\mathrm{p}}$ distributed homogenously in the $\beta$ matrix, Figure 6 . For AC + Aging, $\alpha_{s}$ with a gray contrast precipitated in the residual $\beta$ matrix due to step cooling in furnace and 


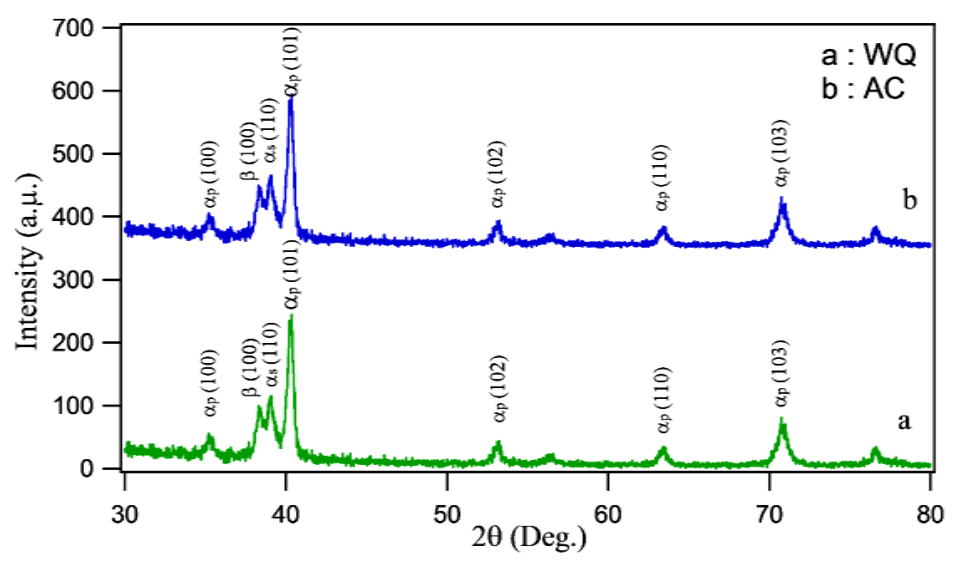

Figure 5. X-Ray diffraction analysis for two types of cooling rates.


Figure 6. FESEM images of aged samples: (a) AC + Aging and (b) WQ + Aging.

also slow cooling rate as well as aging treatment (Figure 6(a)). The volume fractions of $\alpha_{\mathrm{p}}$ and $\alpha_{\mathrm{s}}$ are about $45 \mathrm{vol} \%$ and $20 \mathrm{vol} \%$, respectively. For WQ + Aging, $\alpha_{\mathrm{s}}$ precipitated in the residual $\beta$ matrix due to step cooling in furnace and aging treatment (Figure 6(b)). The volume fractions of $\alpha_{\mathrm{p}}$ and $\alpha_{\mathrm{s}}$ are about $40 \mathrm{vol} \%$ and $15 \mathrm{vol} \%$, respectively. Moreover, fine secondary $\alpha$ platelets were precipitated from the supersaturated $\beta$ phase during solution treatment and aging, Figure 7. These precipitations of $\alpha_{s}$ platelets are regarded as the main reason for strengthening the studied TC21 alloy [16]. This is because these $\alpha_{\mathrm{s}}$ platelets will increase the $\alpha / \beta$ phase boundary. Fine secondary $\alpha$ platelets together with residual $\beta$ phase are called "residual $\beta$ matrix strengthened by fine secondary $\alpha$ platelets" ("residual $\beta$ matrix" for short). Each phase has been verified by X-Ray diffraction analysis, as shown in Figure 8. This result was in agreement with the results that were reported by Shao et al. [16].

\subsection{Mechanical Properties}

\subsubsection{Hardness}

Vickers hardness measurements were carried out to investigate the influence of solution and aging treatments on the as-received TC21 alloy, Figure 9. WQ samples obtained the lowest hardness (HV340) due to the presence of high amount of $\alpha_{\mathrm{p}}$ phase (58\%). While, AC samples revealed a higher hardness 


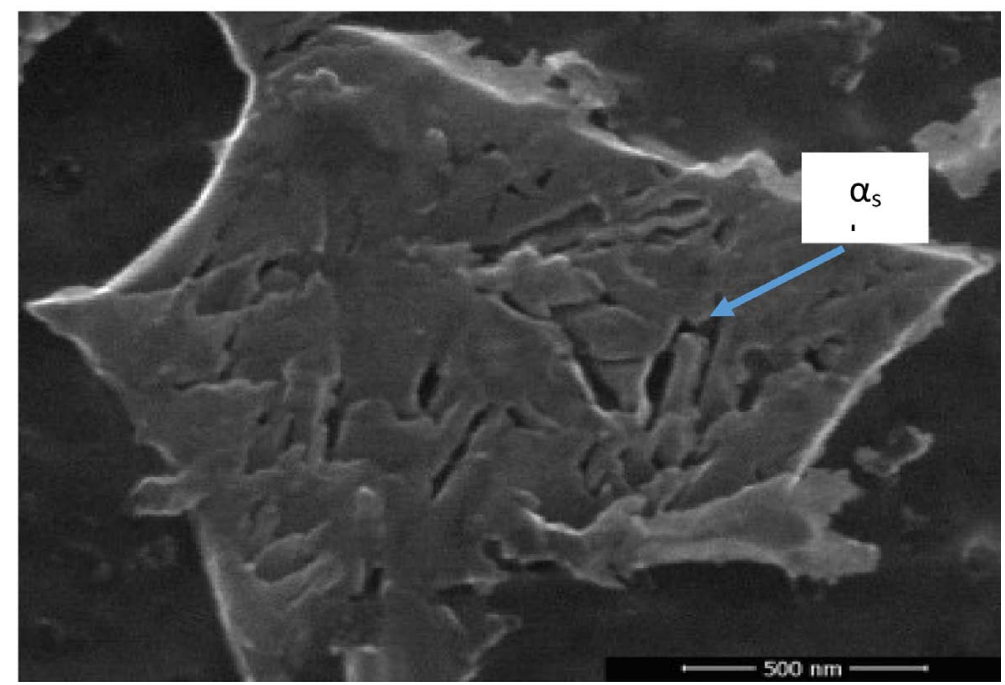

Figure 7. Fine secondary a platelets in residual $\beta$ matrix.

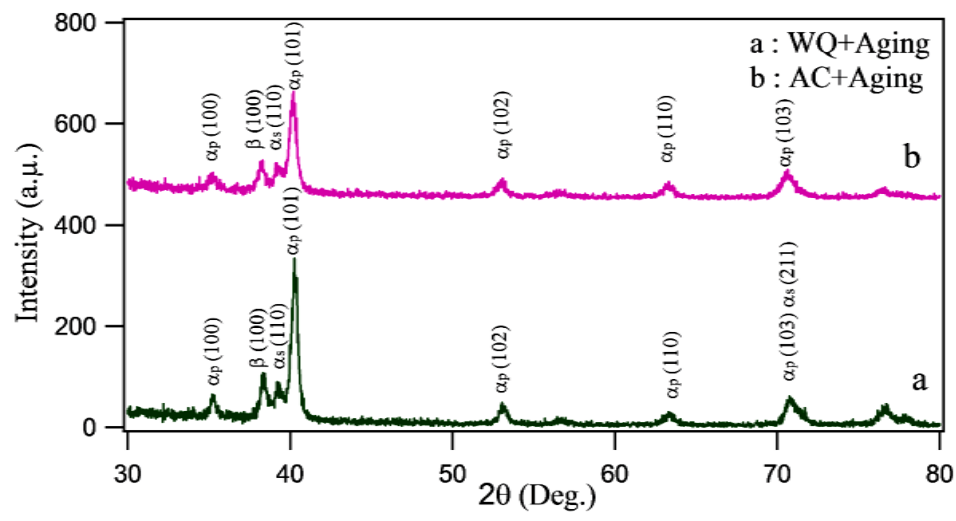

Figure 8. X-Ray diffraction analysis for two types of microstructures.

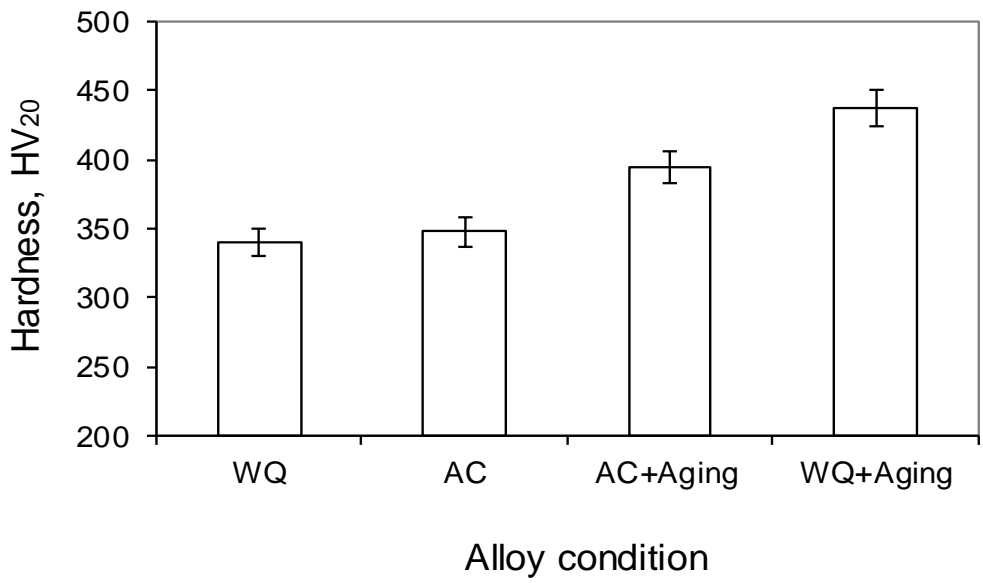

Figure 9. Average hardness values at various conditions.

(HV348) compared to WQ samples due to existing of a lower amount of $\alpha_{\mathrm{p}}$ phase (52\%). AC + Aging samples showed a hardness value of HV395. Moreover, WQ + Aging samples obtained the highest hardness value (HV438) due to 
the presence of a lower amount of $\alpha_{\mathrm{p}}$ phase (40\%) compared to the others. It is also noticed that cooling rate has a relatively small effect on the hardness of TC21 alloy. The variation in hardness with aging treatment is more pronounced. There is an increase in hardness of $29 \%$ in case of WQ + Aging condition compared to WQ condition. Based on hardness results, it can be expected that WQ + Aging condition will show better tribological performance than other conditions.

\subsubsection{Tensile Properties}

Room temperature tensile properties of TC21 alloy after solution treatment with different cooling rates and aging treatment are shown in Figure 10. Cooling rate and aging treatment have an important role on tensile properties of TC21 alloy. Both yield and ultimate strengths increased after aging treatment and of course on the account of ductility. The highest ultimate and yield strengths, reaching $1295 \mathrm{MPa}$ and $1240 \mathrm{MPa}$ respectively, were reported for WQ + Aging samples. But they showed the lowest values of elongation and reduction of area. The effect of $\beta$ strengthening with the $\alpha_{\mathrm{s}}$ was clearly shown for the aged samples after WQ

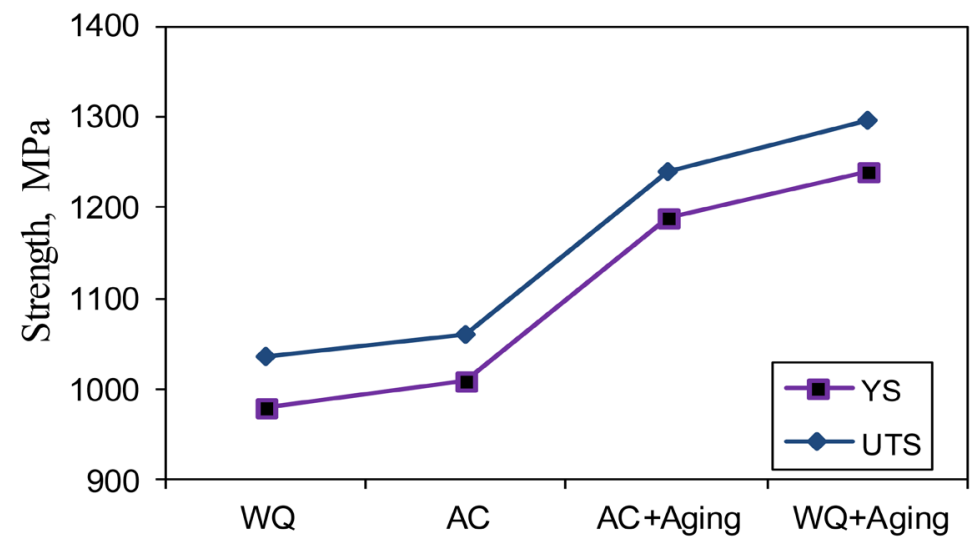

Alloy Condition

(a)

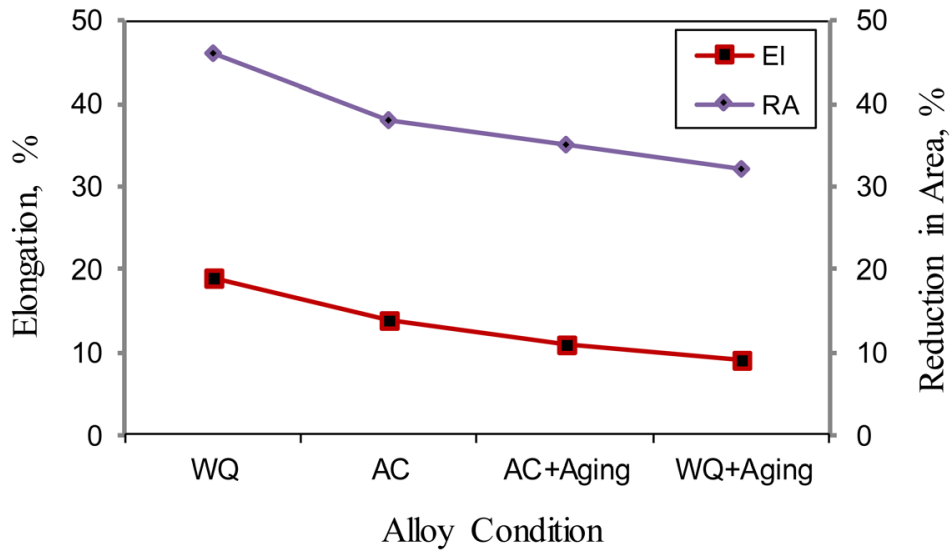

(b)

Figure 10. Variation of UTS, YS, El and RA at various conditions. 
and $\mathrm{AC}$ conditions, where the ultimate tensile strength increased from $1036 \mathrm{MPa}$ to $1295 \mathrm{MPa}$ and from $1061 \mathrm{MPa}$ to $1239 \mathrm{MPa}$, respectively. On the other hand, the elongation decreased from $19 \%$ to $9 \%$ and from $14 \%$ to $11 \%$, respectively.

As expected, WQ + Aging condition revealed the lowest elongation (9\%) and reduction of area (32\%), (Figure 10(b)). Of course, WQ condition obtained the highest elongation and reduction of area compared to others because WQ condition is characterized by low strength and hardness due to the presence of a high amount of $\alpha_{\mathrm{p}}$ phase (58\%). The difference between ultimate tensile and yield strengths was estimated to be $56 \mathrm{MPa}$ for the WQ condition and $55 \mathrm{MPa}$ in case of WQ + Aging condition. On the other hand, this difference was relatively lower for AC and AC + Aging conditions (49 MPa), as seen in Figure 10(a). According to the above results, better comprehensive mechanical properties of TC21 alloy can be achieved by AC + Aging condition for static-dynamic applications, and WQ + Aging condition for static applications only. This finding was in agreement with the results reported by Shi et al. [13].

\subsubsection{Correlation between Tensile Properties and Content of Residual $\beta$ Matrix}

In spite of applying the same solution treatment and aging, the residual $\beta$ matrix exhibited different contents due to the difference in cooling rates. The content of residual $\beta$ matrix has a great influence on tensile strength. As can be seen in Figure 11(a) and Figure 11(b), both ultimate strength and yield strength

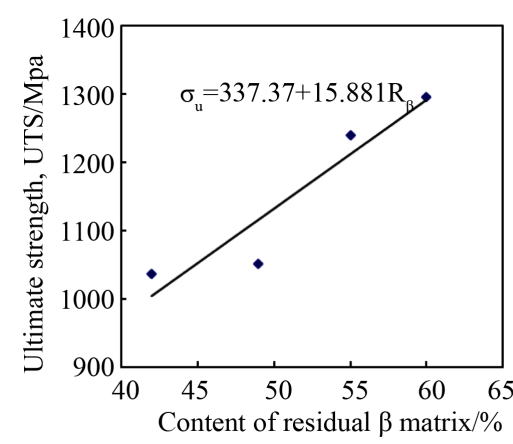

(a)

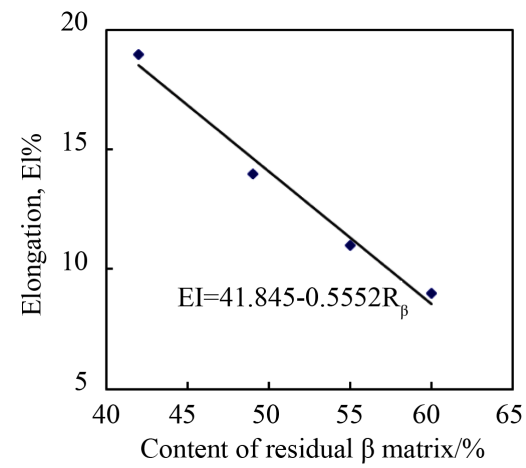

(c)

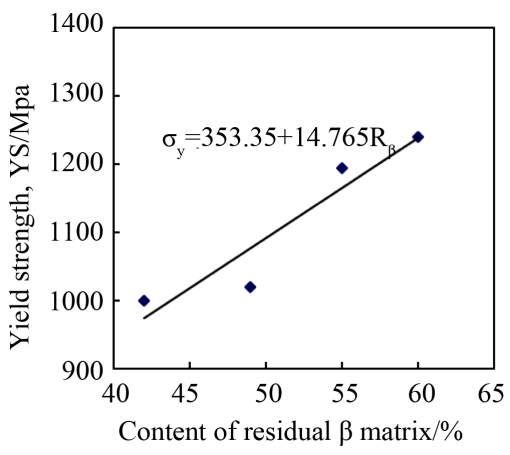

(b)

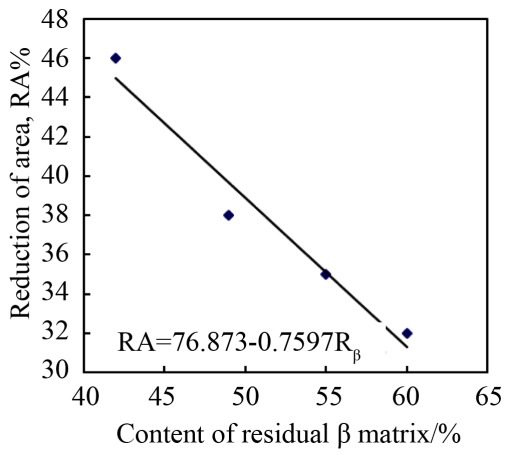

(d)

Figure 11. Relations between tensile properties and Content of residual $\beta$ matrix: (a) U1timate strength; (b) Yield strength; (c) Elongation; (d) Reduction of area. 
showed a rising trend as increasing in content of residual $\beta$ matrix. This phenomenon was also found by Shi et al. [13] and Srinivasu et al. [17]. The strength models as a function of content of residual $\beta$ matrix are set up by experimental data fitting, and the following equations can be expressed:

$$
\begin{aligned}
& \sigma u+337.37+15.881 R \beta \\
& \sigma y+353.34+14.765 R \beta
\end{aligned}
$$

where $\sigma u$ and $\sigma y$ represent ultimate tensile strength, and yield strength, respectively, and $R \beta$ represents the content of residual $\beta$ matrix. The correlation coefficients for ultimate strength and yield strength are 0.943 and 0.949 , respectively, which indicate that both ultimate strength and yield strength have good linear correlations with the content of residual $\beta$ matrix.

The content of residual $\beta$ matrix has also an influence on tensile ductility. As shown in Figure 11(c) and Figure 11(d), with increasing content of residual $\beta$ matrix, both elongation and reduction of area exhibited a downward trend. This phenomenon is directly related to the presence of fine secondary $a$ platelets in the structure. With increasing the amount of fine secondary $\alpha$ platelets, the probability for microcracks increases, and finally the ductility of alloy will be decreased. The ductility models can be also $\mathrm{s} e \mathrm{t}$ as a function of the content of residual $\beta$ matrix by experimental data fitting, and the following equations can be recorded:

$$
\begin{aligned}
& E l+41.845-0.5552 R \beta \\
& R A+68.014-0.6022 R \beta
\end{aligned}
$$

The correlation coefficients for elongation and reduction of area are 0.956 and 0.958 , respectively, which indicated that ductility has good linear correlations with the content of residual $\beta$ matrix. This indicated that the content of residual $\beta$ matrix was one of the factors that influence the ductility of TC21 alloy.

The fracture surface of some selected tensile samples of WQ and AC conditions was examined using field emission scanning electron microscope (FESEM). Fracture surface of AC composed mainly of equiaxed ductile dimples and no flat areas were found (Figure 12(a)). The ductile dimples fall into two categories: 1) narrow ductile dimples which may be induced by separation of single $\alpha$ grain or $\beta$ grain; and 2) wide ductile dimples which may be induced by separation of several $\alpha$ grains [18]. For WQ condition, Figure 12(b), it can be seen that width and depth of equiaxed ductile dimples are increased with increasing cooling rate. As cooling rate increases, the tensile sample necks seriously before fracturing with big deep hallow holes appearing on the surface. In addition, large shrinkage, plenty of deep and big equiaxed ductile dimples were noticed on the fracture surface of WQ condition that proves good tensile elongation.

The fracture mechanisms of $\mathrm{AC}+$ Aging and $\mathrm{WQ}+$ Aging conditions were studied, Figure 13. Fracture surface of AC + Aging condition (Figure 13(a)) consisted mainly of equiaxed ductile dimples and very small percentage of flat 

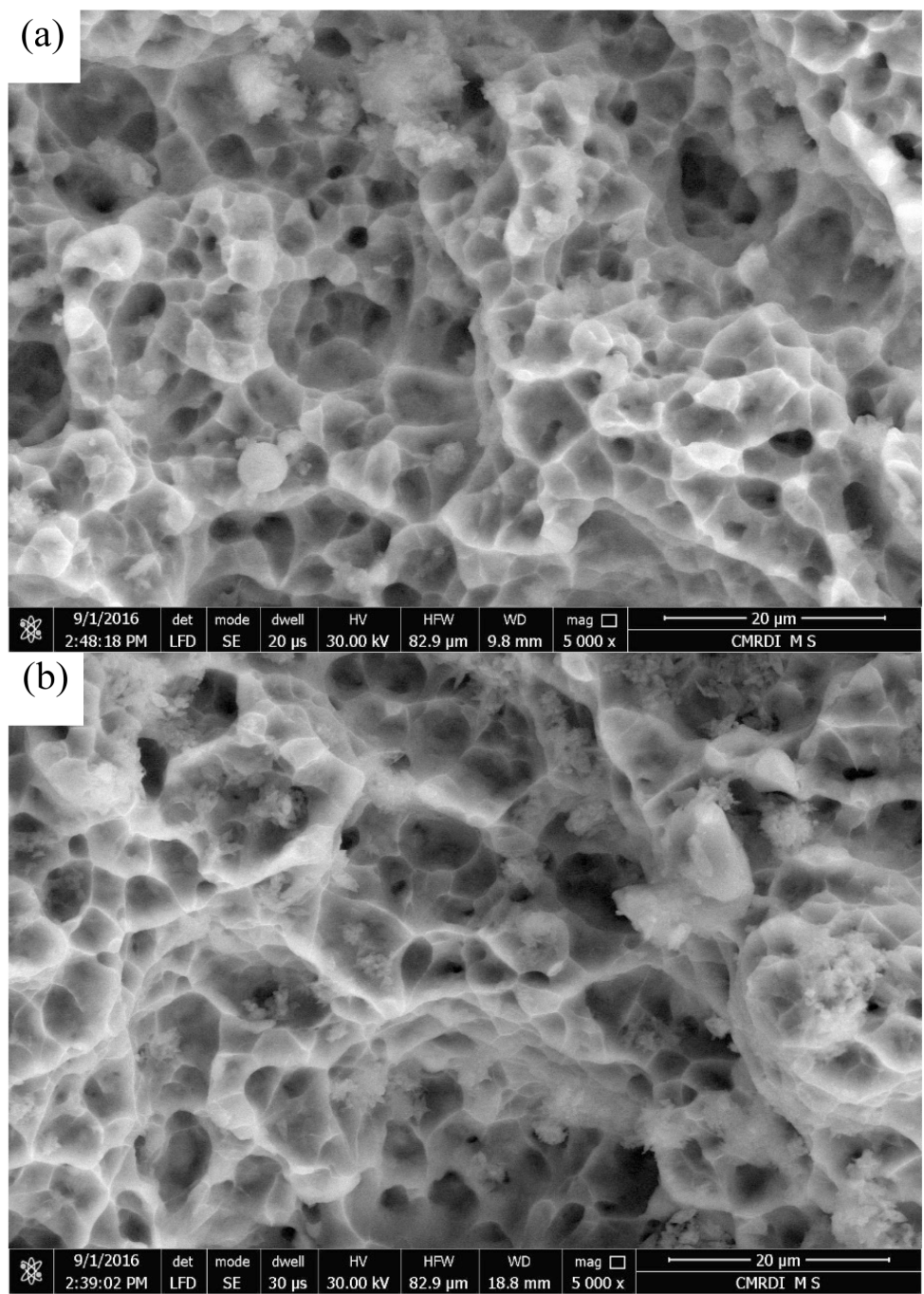

Figure 12. Fracture surface of tensile samples: (a) AC and (b) WQ.

areas. These dimples are relatively smaller and shallower than those existing in cases of AC and WQ conditions. However, fracture surface of WQ + Aging condition (Figure 13(b)) composed mainly of equiaxed dimples and large flat areas resulted from intergranular fracture of $\alpha$ grains. This referred to presence of a mixture of ductile and intergranular fracture, because WQ + Aging condition gave the lowest ductility. Thus, the presence of small shrinkage; small and shallow dimples on the fracture surfaces of WQ + Aging condition proved the low ductility of WQ + Aging samples.

\subsubsection{Wear Properties}

The effect of sliding speed on wear rate of the studied TC21 alloy in all conditions is presented in Figure 14. The estimated wear rates obtained that wear rate for all studied conditions increased with increasing sliding speed up to $1.75 \mathrm{~m} / \mathrm{s}$ and then decreased again at $2 \mathrm{~m} / \mathrm{s}$. Since the wear rate is directly proportional to the real area of contact, WQ + Aging samples showed a lower wear rate. However, WQ samples obtained the highest wear rate compared to the others. The wear 

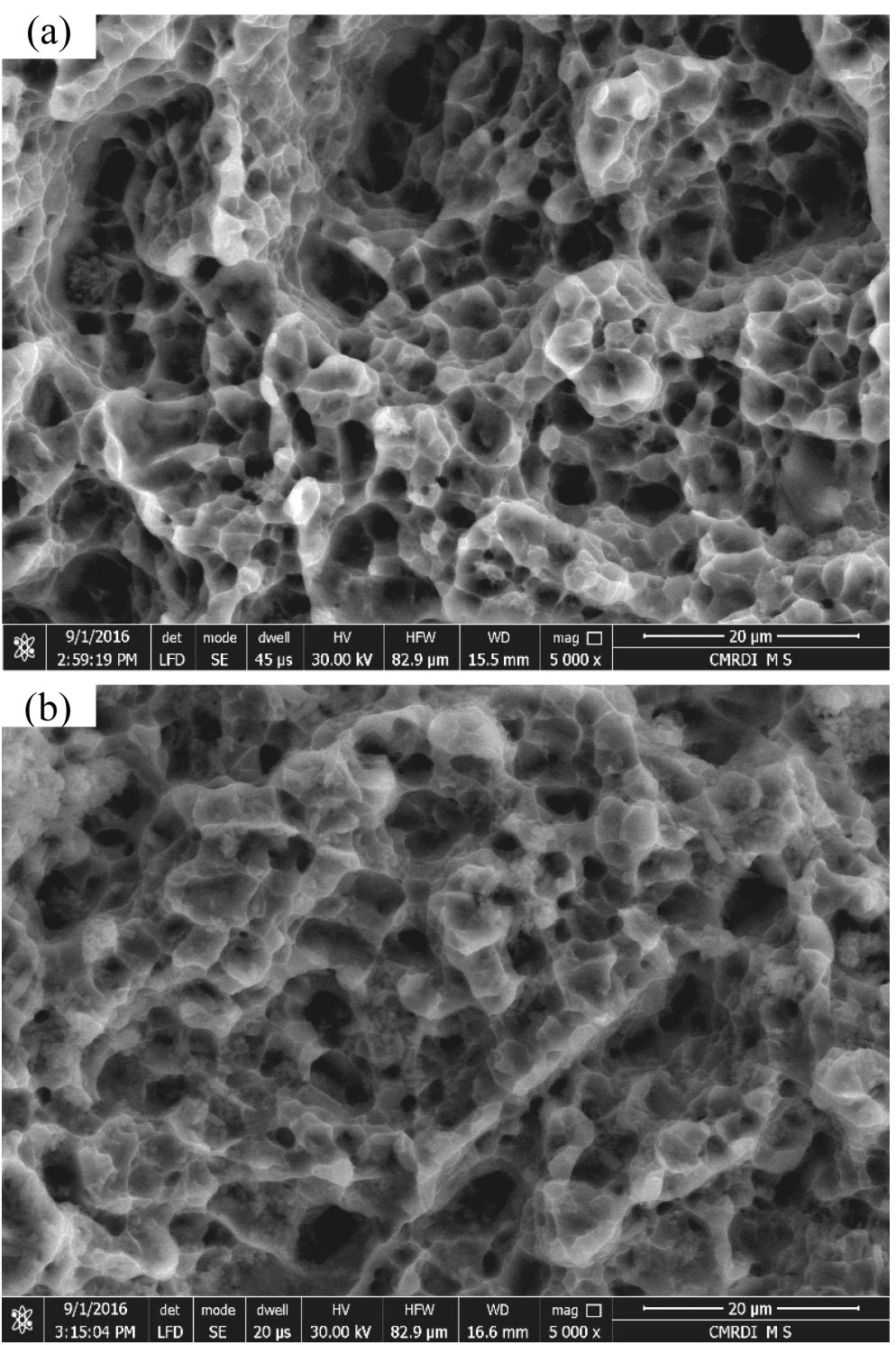

Figure 13. Fracture surface of tensile samples: (a) AC + Aging and (b) WQ + Aging.

rate of WQ samples was approximately one and half times higher than WQ + Aging samples. This may be expected for the as-aged samples, irrespective of microstructure, where they exhibited higher hardness as compared to the samples without aging.

The wear rate of all conditions significantly can be classified into three stages with increasing sliding speed, Figure 14. Initially, the wear rate was rapidly increased with increasing sliding speed up to $1.5 \mathrm{~m} / \mathrm{s}$, and then showed a steady state till $1.75 \mathrm{~m} / \mathrm{s}$ and finally deterioration with further increase in sliding speed up to $2 \mathrm{~m} / \mathrm{s}$. As shown in Figure 14, Stage I showed high wear rate because of the first contact between the sample and rotating ring. In such case, the wear rate will be high till coinciding sample surface with the rotating ring. Because WQ samples had a low hardness, they showed a high amount of wear rate in Stage I. If the sample surface coincided well with the rotating ring, the wear rate will 


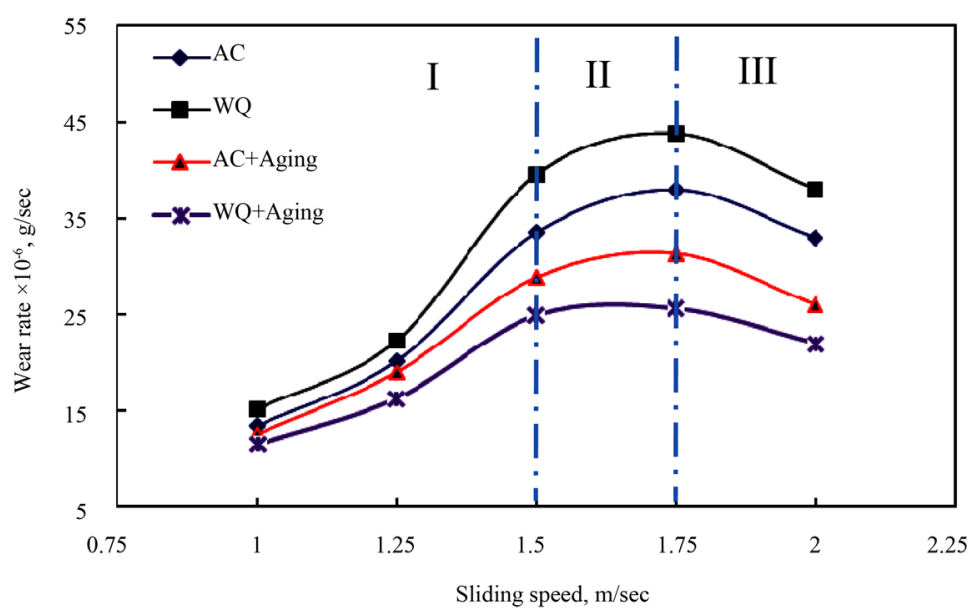

Figure 14. Wear rate of studied TC21 alloy as a function of sliding speed.

reach a steady state which is denoted as Stage II. With increasing sliding speed to $2 \mathrm{~m} / \mathrm{s}$, the temperature of contact surface will be increased. Then, a relative thermal hardening effect will be happened and the wear rate will be decreased. This phase is defined as Stage III.

When the sample surface is first brought into contact with the rotating ring, the wear occurs by removal of high amount of asperities and then initial oxide layer will be formed over the surface. In general, a harder material is able to hold a thicker oxide layer more firmly as compared to a softer one [19]. Hence WQ + Aging condition, which is harder than the others, may be able to hold an oxide layer of a larger critical thickness firmly before it flakes off. Continuing the process of oxide layer removal and reformation as well as thickening, there will be a variation in wear rate. Increasing the difference in wear rate at higher sliding speeds as compared to lower speeds may be explained on the basis of oxide layer formation. This is supported by the XRD analysis that has been done on the worn surface samples at different sliding speeds for WQ condition, Figure 15. XRD analysis showed some diffraction peaks for metallic material and there were no peaks for Fe that transferred from the ring to TC21 samples. As can be seen from Figure 15(a), at lower sliding speed $(1 \mathrm{~m} / \mathrm{s})$, only $\alpha$-Ti was the predominant phase and no oxides could be recognized. In contrast, the XRD patterns at higher sliding speeds $\left(1.75\right.$ and $2 \mathrm{~m} / \mathrm{s}$ ) showed some particles of $\mathrm{TiO}_{2}$ and $\mathrm{Al}_{2} \mathrm{O}_{3}$ oxides that were existing on the worn surfaces (Figure 15(c), Figure 15(d)). The amount of these oxides was relatively very small.

The FESEM micrographs presented in Figure 16 and Figure 17 showed worn surface morphologies for the samples tested at WQ and WQ + Aging conditions with different sliding speeds (1, 1.75 and $2 \mathrm{~m} / \mathrm{s})$. The morphologies of worn surfaces at intermediate sliding speeds $(1.25$ and $1.5 \mathrm{~m} / \mathrm{s})$ are not included in this study because they showed intermediate characteristics between those chosen three extremes. Evidences of abrasion wear can be detected in all tested samples. Continuous sliding marks with plastically deformed grooves and ridges were 


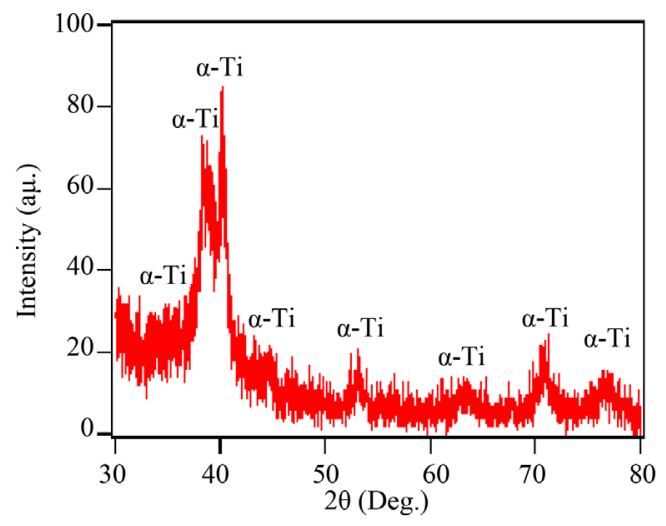

(a)



(b)

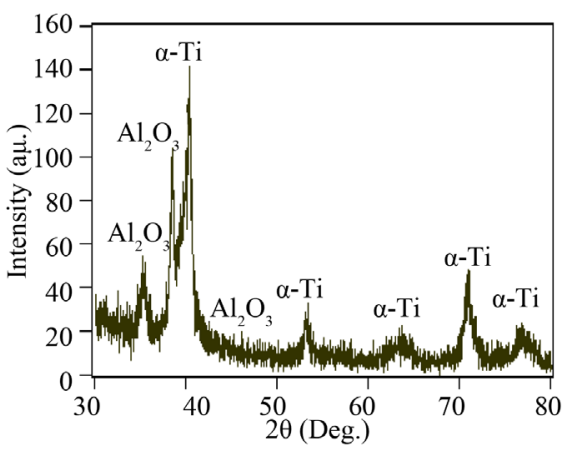

(c)

Figure 15. XRD patterns of the worn surface at speeds of (a) $1 \mathrm{~m} / \mathrm{s}$, (b) $1.75 \mathrm{~m} / \mathrm{s}$ and (c) 2 $\mathrm{m} / \mathrm{s}$.

seen on wear tracks independently of sliding speed. Extent of plastic deformation or "ploughing" is found to be smaller in case of WQ + Aging condition. Layers with plastic deformation were found over the worn surfaces with relatively smooth areas for all sliding speeds.

Shallow grooves resulted from penetrating of hard abrasive particles were observed over the worn surfaces. The penetration depth depends mainly on the relative hardness of abrasive particles with respect to the sample surface hardness. As the hardness of WQ + Aging samples is getting higher than WQ samples, it is expected that depth of penetration in WQ + Aging condition surface became less. In such case, it will produce less material removal due to ploughing action and smaller extent of plastic flow in case of WQ + Aging condition. Thus, $\mathrm{WQ}+$ Aging condition exhibited significantly less wear rate as compared to WQ condition.

FESEM examination for WQ showed that at least two wear mechanisms were existing in those conditions. Existence of flakes removed from contact surface by delamination mechanism (Figure 16(d)) strongly suggests the occurrence of adhesive wear. During sliding, the contacting asperities experience an incremental plastic deformation, which accumulated during the multi-contacts [19]. When a critical value of this accumulated plastic strain is attained, subsurface cracks will be nucleated and then propagated till a critical condition. Consequently, 

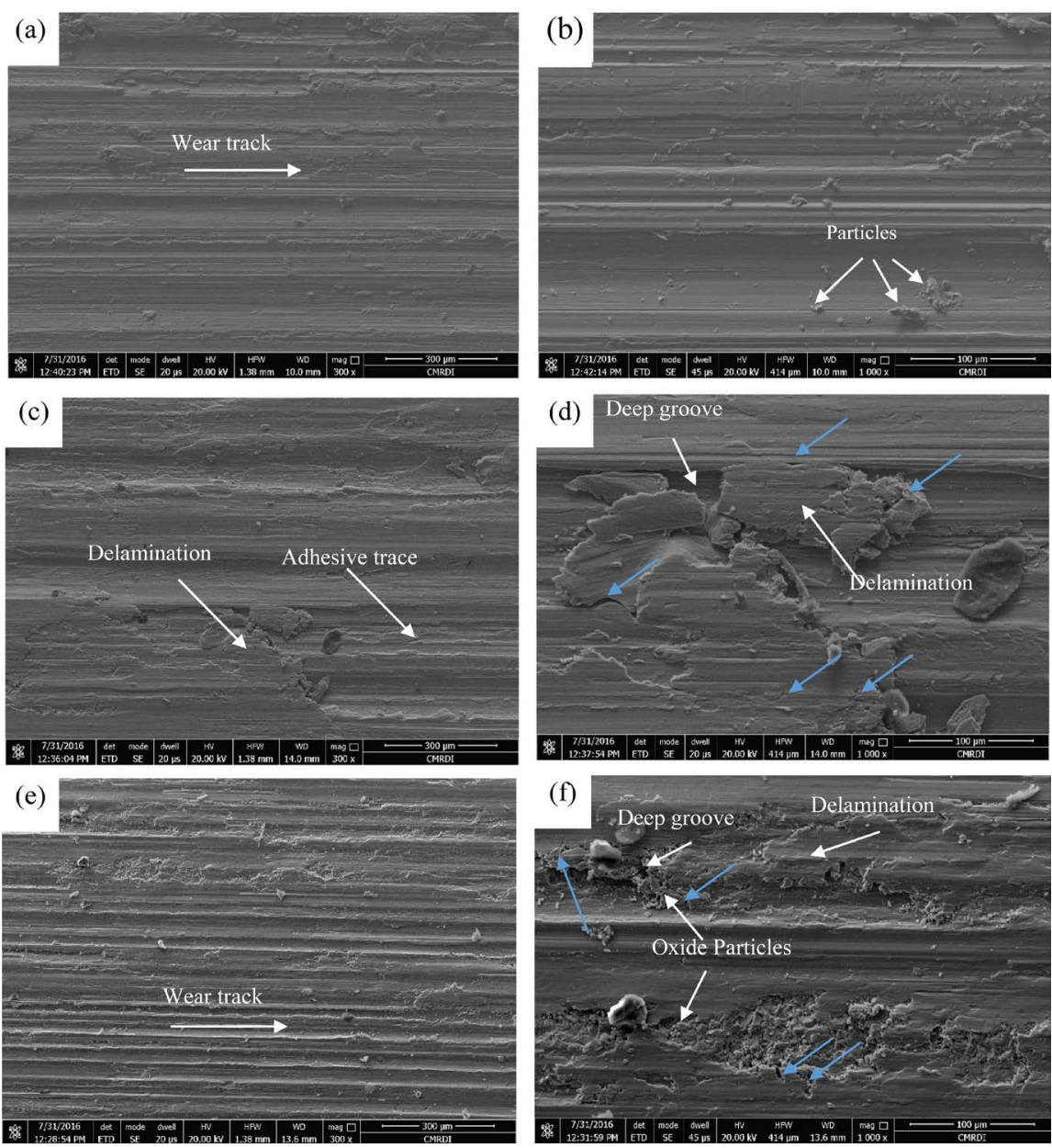

Figure 16. Worn surfaces of the WQ at $1 \mathrm{~m} / \mathrm{s}$ (a) (b); $1.75 \mathrm{~m} / \mathrm{s}$ (c) (d); and $2 \mathrm{~m} / \mathrm{s}$ (e) (f).

flakes of material were detached from the surface by adhesion to the ring surface and forming a transfer layer. Some of the transferred material is lost, but some was still re-embedded and smeared over the contact surface. For this theory of delamination, successive discussion and implementation by numerous authors [19] [20] supposed that a critical plastic strain is given by the materials ductility, i.e. it is governed by the $\alpha / \beta$ grain boundaries [21]. Titanium and its alloys are chemically active and have a high ductility that will be oriented to adhesion mechanism [22]. The adhesive strength of the formed junctions is usually much higher than the strength of titanium alloy. Such junctions will rupture within the weak titanium asperities, which accounted for many craters on the worn surface [22]. The removal of materials by adhesion will lead to a large wear rate. Thus, it can be observed here that WQ condition revealed the highest wear rate due to severe delamination wear mechanism acting on the worn surface.

The worn surfaces of WQ condition (Figure 16) showed rough worn surfaces, abrasive grooves with extensive plastic deformation and traces of local material removal by delamination process. These worn surfaces indicated actually to severe wear. Moreover, some fracture and large flakes removed from the worn surface were observed. Detailed investigation for delaminated regions reveals 
ridges and many cracks either at parallel or right angle to sliding direction as indicated by arrows in Figure 16(d). Closer observation of wear tracks reveals also large flakes removed from the surface (Figure 16(d), Figure 16(f)), which indicated to delamination wear mechanism. This is probably due to a relatively greater contact between the sample and rotating ring. In addition, discrete patches of material smeared can be easily detected on the worn surfaces. These features indicated to the wear that occurred predominantly by adhesion. In such case, adhesion overlaps the abrasion and accelerated the wear process for WQ condition. Although there was some moderate adhesive wear damage, it was evident that two wear mechanisms, abrasive and adhesive, were more pronounced at low speeds. The ring surface was also examined to prove this phenomenon. The same wear mechanism was observed by examining sample worn surfaces at a low speed of $1.0 \mathrm{~m} / \mathrm{s}$ (Figure 16(a), Figure 16(b)). Formation and removal of transferred layers produced by delamination wear and an increase in the amount of wear rate, which was much higher than the other conditions. It is obvious that wear behavior of WQ condition strongly depends on its hardness. Occurrence of delamination was more prominent when wear tests are carried out at high sliding speeds of 1.75 and $2 \mathrm{~m} / \mathrm{s}$ (Figures 16(d)-(f)). The same behavior was observed by Cvijovic' et al. [19], who found that adhesive wear mechanism was dominant in wear testing of Ti-Nb-Zr alloy.

The worn surface morphology of WQ + Aging condition is shown in Figure 17. WQ + Aging worn surfaces showed similar worn surfaces feature as WQ samples. Noticeable "ploughing" was found, irrespective of the tribological sliding speeds. Continuous damaged layers in a brittle manner and abrasive grooves aligned in the direction of sliding can be clearly detected (Figure 17(a), Figure 17(c), Figure 17(e)). It could be suggested that abrasive wear mechanism was mainly pronounced. FESEM investigation of WQ + Aging worn surfaces showed delamination with a lower degree of severity and some patches of smeared material (Figure 17(c), Figure 17(d)). Each type of damage was observed in various degrees on the worn surfaces at different sliding speeds. Patches of smeared material found to decrease as sliding speed is increased to $2.0 \mathrm{~m} / \mathrm{s}$ (Figure 17(e), Figure 17(f)). Smooth appearance of worn surface and small extent of plastic flow were the indication of getting better resistance of WQ + Aging samples to plastic deformation compared to WQ samples. As can be seen in Figure 17, the severity of abrasion was significantly lower. This may be expected, since the wear rate of WQ + Aging samples was one and half orders in magnitude lower than of WQ samples. The presence of patches and traces of local material removal could not be easily detected, especially on the worn surfaces tested at low sliding speed (Figure 17(a), Figure 17(b)).

\section{Conclusions}

From the experimental results related to microstructure, hardness, tensile properties and wear characteristics of TC21 alloy subjected to different heat treatment processes, the following conclusions can be drawn: 
(a)



(c)

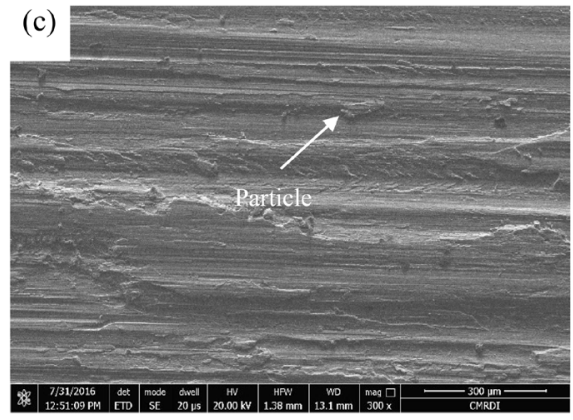

(e)

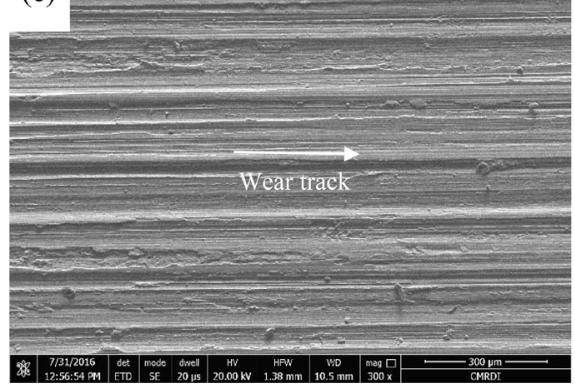

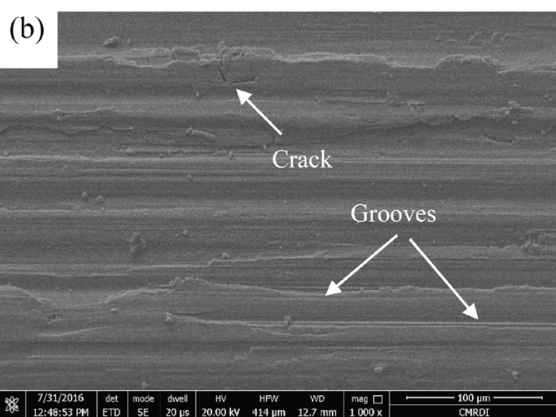

(d)

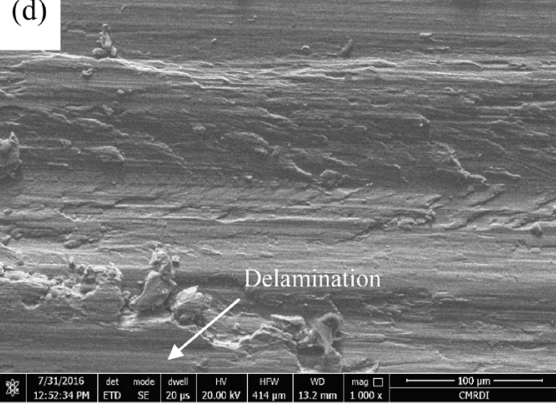

(f)

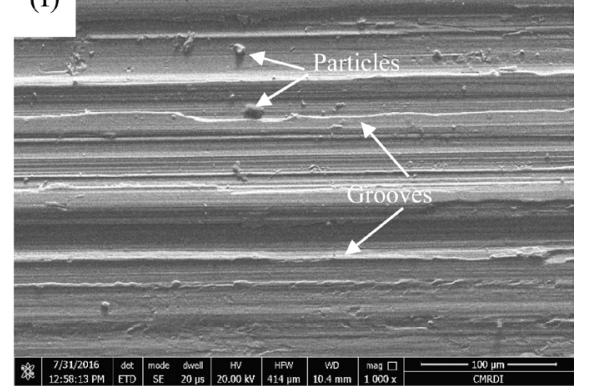

Figure 17. Worn surfaces of the WQ +Aging at $1 \mathrm{~m} / \mathrm{s}$ (a) (b); $1.75 \mathrm{~m} / \mathrm{s}$ (c) (d); and $2 \mathrm{~m} / \mathrm{s}$ (e) (f).

1) Duplex stage solution treatment with two different cooling rates and aging treatment, produced a structure consisted of secondary $\alpha$ phase precipitated in a residual $\beta$ phase due slow cooling rate from $900^{\circ} \mathrm{C}$ to $800^{\circ} \mathrm{C}$ inside furnace or the final slow cooling rate by air as well as the aging treatment. Fine secondary $\alpha$ platelets and residual $\beta$ phase formed a residual $\beta$ matrix;

2) Cooling rate has a relatively small effect on hardness of the studied TC21 alloy. The variation in hardness with aging treatment was more pronounced;

3) Microstructure of TC21 alloy composed mainly of $\alpha$ phase and residual $\beta$ matrix strengthened by secondary $\alpha$ platelets;

4) Optimal hardness, tensile properties and wear resistance can be achieved by $\mathrm{AC}+$ Aging condition, however wear resistance is found to be slightly lower for WQ + Aging condition;

5) Tensile fractured surface morphologies for WQ condition showed equiaxed dimple feature with good ductility, and WQ + Aging condition obtained intergranular and equiaxed dimple fractured mechanism with poor ductility;

6) The highest wear rate was obtained for WQ condition. However, the lowest 
wear rate was given for WQ + Aging condition due to its high hardness. In addition, wear rate of all conditions increased with increasing sliding speed until 1.75 $\mathrm{m} / \mathrm{s}$ and then decreased with increasing sliding speed of $2 \mathrm{~m} / \mathrm{s}$.

7) Abrasion wear mechanism was noticed in WQ + Aging samples. Adhesion, transfer layer formation and cracking wear mechanisms were observed in case of WQ samples. At low sliding speed, micro fragmentation wear mechanism was observed, and brittle detachment of large particles wear mechanism was obtained at high sliding speed.

\section{References}

[1] Lütjering, G. and Williams, J.C. (2007) Titanium. 2nd Edition, Springer, Berlin Heidelberg.

[2] Banerjee, D. and Williams, J.C. (2013) Perspectives on Titanium Science and Technology. Acta Materialia, 61, 844-879. https://doi.org/10.1016/j.actamat.2012.10.043

[3] Ibrahim, K.M., EL-Hakeem, A.M. And Elshaer, R.N. (2013) Microstructure and mechanical Properties of Cast and Heat Treated Ti-6.55Al-3.41Mo-1.77Zr Alloy. Transactions of Nonferrous Metals Society of China, 23, 3517-3524.

[4] Lia, G., Xia, F., Gao, Y. and He, Y. (2016) Microstructure Control Techniques in Primary Hot Working of Titanium Alloy Bars: A Review. Chinese Journal of Aeronautics, 29, 30-40.

[5] Wang, L., Zang, Q.Y., Li, X.X., Cui, X.H. and Wang, S.Q. (2014) Severe-to-Mild Wear Transition of Titanium Alloys as a Function of Temperature. Tribology Letters, 53, 511-520. https://doi.org/10.1007/s11249-013-0289-5

[6] Zang, Q.Y., Zhou, Y., Li, X.X., Wang, L., Cui, X.H. and Wang, S.Q. (2016) Accelerated Formation of Tribo-Oxide Layer and Its Effect on Sliding Wear of a Titanium Alloy. Tribology Letters, 63, 1-13.

[7] Ceschini, L., Lanzoni, E., Martini, C., Prandstraller, D. and Sambogna G. (2008) Comparison of Dry Sliding Friction and Wear of Ti6Al4V Alloy Treated by Plasma Electrolytic Oxidation and PVD Coating. Wear, 264, 86-95.

[8] Tang, B., Kou, H., Wang, Y., Zhu, Z., Zhang, F. and Li, J. (2012) Kinetics of Orthorhombic Martensite Decomposition in TC21 Alloy under Isothermal Conditions. Journal of Materials Science, 47, 521-529.

https://doi.org/10.1007/s10853-011-5829-5

[9] Xing, D.D., Xin, L.D., Li, M.B. and Hua, Z.X. (2013) Effects of Pretreatment and HVOF Sprayed Cermet Coating on Fatigue Properties of TC21 titanium Alloy. Science China Technological Sciences, 56, 1029-1037. https://doi.org/10.1007/s11431-013-5149-x

[10] Wang, Y.H., Kou, H.C., Chang, H., Zhu, Z.S., Zhang, F.S., Li, J.S. and Zhou, L. (2009) Influence of Solution Temperature on Phase Transformation of TC21 Alloy. Materials Science and Engineering A, 508, 76-82.

[11] Wen, L., Xiao, M., Zhi, H., Ya, L., Heng, Q., Yi, Z. and Zheng, X. (2010) Effect of Heat Treatment on Microstructures and Mechanical Properties of TC21 Alloy Large Bar. Titanium Industry Process, 27, 28-31.

[12] Shi, Z.F., Guo, H.Z., Han, J.Y. and Yao, Z.K. (2013) Microstructure and Mechanical Properties of TC21 Titanium Alloy after Heat Treatment. Transactions of Nonferrous Metals Society of China, 23, 2882-2889.

[13] Shi, Z.F., Guo, H.Z., Liu, R., Wang, X.C. and Yao, Z.K. (2015) Microstructure and 
Mechanical Properties of TC21 Titanium Alloy by Near-Isothermal Forging. Transactions of Nonferrous Metals Society of China, 25, 72-79.

[14] Jia, Z., Zeng, W., Zha, Y., Shi, C., Qua, B. and Wu, J. (2015) The Color Changes and Tensile Properties of Oxidized Ti-6A1-2Mo-1.5Cr-2Zr-2Sn-2Nb Alloy. Journal of Alloys and Compounds, 640, 488-496.

[15] Tan, C., Li, X., Sun, Q., Xiao, L., Zhao, Y. and Sun, J. (2015) Effect of $\alpha$-Phase Morphology on Low-Cycle Fatigue Behavior of TC21 Alloy. International Journal of Fatigue, 75, 1-9.

[16] Shao, H., Zhao, Y., Ge, P. and Zeng, W. (2013) Crack Initiation and Mechanical Properties of TC21 Titanium Alloy with Equiaxed Microstructure. Materials Science \& Engineering $A, 586,215-222$.

[17] Srinivasu, G., Natraj, Y., Bhattacharjee, A., Nandy, T.K. and Nageswara, G.V.S. (2013) Tensile and Fracture Toughness of High Strength $\beta$ Titanium Alloy, Ti-10V-2Fe-3Al, as a Function of Rolling and Solution Treatment Temperatures. Materials and Design, 47, 323-330.

[18] Li, H., Li, M., Luo, J. and Wang, K. (2015) Microstructure and Mechanical Properties of Heat-Treated Ti-5Al-2Sn-2Zr-4Mo-4Cr. Transactions of Nonferrous Metals Society of China, 25, 2893-2900.

[19] Cvijovic-Alagic, I., Cvijovic, Z., Mitrovic, S., Rakin, M., Panic, Đ. and Babic, M. (2011) Wear and Corrosion Behavior of Ti-24Al-11Nb and Ti-6Al-4V Alloys in Simulated Physiological Solution. Corrosion Science, 53, 796-808.

[20] Cvijovic-Alagic, I., Cvijovic, Z., Mitrovic, S., Rakin, M., Veljovic, Đ. and Babic, M. (2010) Tribological Behaviour of Orthopaedic Ti-13Nb-13Zr and Ti-6Al-4V Alloys. Tribology Letters, 40, 59-70. https://doi.org/10.1007/s11249-010-9639-8

[21] Straffelini, G. and Molinari, A. (1999) Dry Sliding Wear of Ti-6Al-4V Alloy as Influenced by the Counterface and Sliding Conditions. Wear, 236, 328-338.

[22] Dong, H. and Bell, T. (2000) Enhanced Wear Resistance of Titanium Surfaces by a New Thermal Oxidation Treatment. Wear, 238, 131-137. 